\title{
Results of postoperative radiochemotherapy of the patients with resectable gastroesophageal junction adenocarcinoma in Slovenia
}

\author{
Ana Jeromen, Irena Oblak, Franc Anderluh, Vaneja Velenik, Marija Skoblar Vidmar, \\ Ivica Ratoša
}

Department of Radiotherapy, Institute of Oncology Ljubljana, Slovenia

Radiol Oncol 2012; 46(4): 337-345.

Received 8 May 2012

Accepted 27 July 2012

Correspondence to: Assist Prof Irena Oblak, MD, PhD, Department of Radiotherapy, Institute of Oncology Ljubljana, Zaloška 2, 1000 Ljubljana, Slovenia. Phone: +386 15879 515; Fax: +386 15879304 407; E-mail: ioblak@onko-i.si

Disclosure: No potential conflicts of interest were disclosed.

Background. Although the incidence of adenocarcinomas of the gastroesophageal junction (GEJ) is sharply rising in the Western world, there are still some disagreements about the staging and the treatment of this disease. The aim of this retrospective study was to analyse the effectiveness and safety of postoperative radiochemotherapy in patients with a GEJ adenocarcinoma treated at the Institute of Oncology Ljubljana.

Patients and methods. Seventy patients with GEJ adenocarcinoma, who were treated with postoperative radiochemotherapy between January 2005 and June 2010, were included in the study. The treatment consisted of 6 cycles of chemotherapy with 5-FU and cisplatin and concomitant radiotherapy with the total dose of $45 \mathrm{~Gy}$.

Results. Twenty-six patients (37.1\%) completed the treatment according to the protocol. The median follow-up time was 17.7 months (range: 3.3-64 months). Acute toxicity grade 3 or more, such as stomatitis, dysphagia, nausea or vomiting, and infection, occurred in $2.9 \%, 34.3 \%, 38.6 \%$ and $41.5 \%$ of patients, respectively. At 3 years locoregional control (LRC), disease-free survival (DFS), disease-specific survival (DSS) and overall survival (OS) were $78.2 \%, 25.3 \%, 35.8 \%$, and $33.9 \%$, respectively. In the multivariate analysis of survival, splenectomy and level of Ca 19-9 >20 kU/L before the adjuvant treatment were identified as independent prognostic factors for lower DFS, DSS and OS. Age <60 years, higher number of involved lymph nodes and advanced disease stage were identified as independent prognostic factors for lower DSS and OS.

Conclusions. In patients with GEJ adenocarcinoma who first underwent surgery, postoperative radiochemotherapy is feasible, but we must be aware of a high risk of acute toxic side effects.

Key words: gastroesophageal junction adenocarcinoma; postoperative radiochemotherapy; toxicity

\section{Introduction}

Adenocarcinomas of the gastroesophageal junction (GEJ) represent a heterogeneous group of tumours with poor prognosis. They are defined as tumours, which arise within $5 \mathrm{~cm}$ proximal or distal to the esophagogastric junction. ${ }^{1}$ Despite a dramatic rise in the incidence of GEJ adenocarcinomas in the Western world ${ }^{2}$, there are still some uncertainties and disagreement about the staging and the treatment of this disease. In the past, GEJ adenocarcinomas were staged either as an oesophageal or gastric cancers, depending on the centre of the tumour. According to the UICC $7^{\text {th }}$ criteria, they are now classified along oesophageal adenocarcinom ${ }^{3}$, although some investigators still consider them to be stomach carcinomas. Most of us agree that these tumours should be treated separately from other tumours of stomach and oesophagus, because they differ in terms of epidemiology, pathogenesis, surgical approach and in prognosis, as well. Based on the anatomic location of the tumour centre, GEJ adenocarcinomas are subclassified by Siewert into three types: type I are tumours of distal oesopha- 
gus; type II tumours (also termed true carcinomas of the cardia) arise immediately at the gastroesophageal junction; type III tumours have subcardial centre with predominant involvement of the proximal stomach or gastric cardia. ${ }^{1}$

The principal treatment of nonmetastatic GEJ adenocarcinomas is the surgical resection like in others gastrointestinal tumours. ${ }^{4-6}$ There exist several different surgical approaches, depending on the localization of tumour, but the common goal is en-bloc removal of the entire tumour with adequate lymphadenectomy. The locoregional disease recurrence is observed in $25-80 \%$ of patients operated on. ${ }^{7,8} \mathrm{~A}$ number of studies were carried out in order to try to improve the survival of the patients with GEJ adenocarcinomas. Uncertainties still remain, because GEJ patients were included either in gastric or oesophageal cancer studies. ${ }^{9-14}$ Therefore, the optimal multimodal treatment strategy is still to be determined. However, it is clear that the patients with T2, T3 and/or N+ disease need additional treatment to surgery alone.

Preoperative chemotherapy with epirubicine (E), cisplatin (C) and fluorouracile (FU), or CFU regimen improves the overall survival in some, but not in all trials.9,15-17 Preoperative radiochemotherapy trials gave mixed results ${ }^{10,11}$, but meta-analysis comparing preoperative chemotherapy with chemoradiotherapy confirmed that the trimodal therapy has higher 2 -years overall survival rate ( $13 \%$ vs. $7 \%){ }^{18}$

Randomized studies of adjuvant radiotherapy only did not report any benefit. ${ }^{19,20}$ Benefit of adjuvant chemotherapy only is also questionable. . $2,21,22^{2}$ However, Intergroup 0116, a randomized phase III trial of adjuvant radiochemotherapy, showed benefit for adjuvant radiochemotherapy compared to observation only after the surgery. In the study, 556 patients with resected gastric cancer were included, $20 \%$ of them with the adenocarcinomas of GEJ. Higher 3-years disease free survival (48\% vs. 31\%; $\mathrm{p}=0.001)$ and 3 -years overall survival ( $50 \%$ vs. $41 \%$; $\mathrm{p}=0.005$ ) were observed for patients treated with surgery and adjuvant radiochemotherapy compared to those treated with surgery only. Critic of this trial was the lack of optimal lymphadenectomy, since only $10 \%$ of patients had D2 lymphadenectomy and only $36 \%$ had D1 lymphadenectomy. The rest of patients underwent D0 lymphadenectomy. It has been postulated that adjuvant radiochemotherapy compensated for suboptimal surgical procedures thus resulting in an overestimation of the survival benefit. ${ }^{13}$ Despite these doubts there has also been proved benefit of adjuvant chemoradiotherapy after D2 lymphadenectomy in the study of Kim et al. with 544 patients. ${ }^{14}$
However, no comparative data of all these multimodal approaches have been published so far.

In the Institute of Oncology Ljubljana, nowadays preoperative chemoradiotherapy is the treatment of choice. There are still some patients with locoregionally advanced disease in whom the surgical resection is performed as the first treatment, followed by postoperative radiochemotherapy. Some of these patients have tumours clinically staged as T1-2 N0, but at the time of the surgery more advanced disease is determined. Some other patients have advanced but technically resectable disease with profuse bleeding or other conditions that require an immediate surgical intervention.

The main endpoints of this retrospective study were to find locoregional control (LRC), diseasefree survival (DFS), disease-specific survival (DSS), and overall survival (OS) in patients with resectable GEJ adenocarcinoma, who were treated with postoperative radiochemotherapy in Slovenia in the period $2005-2010$.

\section{Patients and methods}

\section{Patients and tumour characteristics}

In the period from January 2005 to June 2010, 70 patients (55 males and 15 females; aged 34-77 years, mean age 60 years) were treated for nonmetastatic adenocarcinoma of GEJ with postoperative concomitant chemoradiation at the Institute of Oncology Ljubljana, Slovenia. As the Institute of Oncology is the only hospital in Slovenia with radiotherapy facilities, this number represents the total population of patients with operable GEJ adenocarcinomas treated with adjuvant radiochemotherapy in the country. All patients had locally or regionally advanced disease without distant metastases (stages IIa-IIIc) (Table 1).

\section{Surgical treatment}

Of 70 patients, 63 (90\%) were operated on in two major surgical centres in Slovenia, at the University Medical Centres in Maribor and Ljubljana, and the remaining 7 (10\%) patients in one of the Slovenian regional hospitals. Proximal subtotal resection of the stomach was performed in 3 patients $(4.3 \%)$, total resection of the stomach in 48 patients $(68.5 \%)$, transhiatal esophagogastrectomy in 14 patients $(20 \%)$, and transthoracal esophagogastrectomy in 5 patients $(7.1 \%)$. As determined on the histopathological examination of surgical specimen, the radical resection (R0) was performed in $56(80 \%)$ 
TABLE 1. Patients and tumour characteristics

\begin{tabular}{|c|c|c|c|}
\hline Characteristics & & No. & $\%$ \\
\hline \multirow[t]{2}{*}{ Gender } & Male & 55 & 78.6 \\
\hline & Female & 15 & 21.4 \\
\hline \multirow{4}{*}{$\begin{array}{l}\text { Tumour } \\
\text { classification } \\
\text { by Siewert }\end{array}$} & Type I & 10 & 14.3 \\
\hline & Type ॥ & 14 & 20 \\
\hline & Type III & 32 & 45.7 \\
\hline & Undetermined & 14 & 20 \\
\hline \multirow[t]{4}{*}{ PT - stage } & 1 & 0 & 0 \\
\hline & 2 & 23 & 32.9 \\
\hline & 3 & 41 & 58.5 \\
\hline & 4 & 6 & 8.6 \\
\hline \multirow[t]{4}{*}{$\mathrm{pN}$ - stage } & 0 & 5 & 7.1 \\
\hline & 1 & 26 & 37.1 \\
\hline & 2 & 25 & 35.7 \\
\hline & 3 & 14 & 20 \\
\hline \multirow[t]{5}{*}{ Overall stage } & Ila & 4 & 5.7 \\
\hline & $11 \mathrm{~b}$ & 11 & 15.7 \\
\hline & IIla & 25 & 35.7 \\
\hline & IIlb & 13 & 18.6 \\
\hline & IIIC & 17 & 24.3 \\
\hline \multirow[t]{4}{*}{$\begin{array}{l}\text { Tumour } \\
\text { differentiation }\end{array}$} & Well & 5 & 7.1 \\
\hline & Moderately & 20 & 28.6 \\
\hline & Poor & 39 & 55.7 \\
\hline & Unknown & 6 & 8.6 \\
\hline \multirow[t]{4}{*}{$\begin{array}{l}\text { Surgical } \\
\text { procedures }\end{array}$} & $\begin{array}{l}\text { Transhiatal } \\
\text { oesophagogastrectomy }\end{array}$ & 14 & 20 \\
\hline & $\begin{array}{l}\text { Transthoracic } \\
\text { oesophagogastrectomy }\end{array}$ & 5 & 71 \\
\hline & $\begin{array}{l}\text { Proximal subtotal } \\
\text { gastrectomy }\end{array}$ & 3 & 4.3 \\
\hline & Total gastrectomy & 48 & 68.5 \\
\hline \multirow[t]{2}{*}{ Surgical margins } & Negative & 56 & 80 \\
\hline & Positive & 14 & 20 \\
\hline \multirow[t]{3}{*}{$\begin{array}{l}\text { Perineurial } \\
\text { invasion }\end{array}$} & Yes & 39 & 55.7 \\
\hline & No & 16 & 22.9 \\
\hline & Unknown & 15 & 21.4 \\
\hline \multirow{3}{*}{$\begin{array}{l}\text { Lymphovascular } \\
\text { invasion }\end{array}$} & Yes & 40 & 57.1 \\
\hline & No & 6 & 8.6 \\
\hline & Unknown & 24 & 34.3 \\
\hline \multirow[t]{3}{*}{ Angioinvasion } & Yes & 20 & 28.6 \\
\hline & No & 23 & 32.9 \\
\hline & Unknown & 27 & 38.6 \\
\hline
\end{tabular}

$\mathrm{pT}=$ pathological $\mathrm{T}$-stage; $\mathrm{pN}=$ pathological $\mathrm{N}$-stage patients and in the remaining $14(20 \%)$ patients non-radical surgery was performed - $\mathrm{R} 1$ resection in 11 patients ( $15.7 \%$ ) and $\mathrm{R} 2$ in 3 patients (4.2\%).

\section{Tumour characteristics}

Most frequently (in 32 patients; $45.7 \%$ ), the primary tumour originated in the subcardial stomach and infiltrated the GEJ (Siewert III). In 10 patients $(14.3 \%)$ tumour originated in the distal oesophagus (Siewert I) and in 14 patients $(20 \%)$ in the cardia (Siewert II). In 14 patients $(20 \%)$ the tumours extended over large area and for this reason their classification was not possible. The tumour was staged as pT2 in 23 patients (32.8\%), pT3 in 41 patients (58.6\%) and as pT4 in 6 patients (8.6\%). Sixtyfive patients $(92.9 \%)$ had $\mathrm{N}+$ disease (Table 1$)$.

\section{Investigations before and during therapy}

After the surgery, all patients with the disease of pathological stage II or higher, were presented to a multidisciplinary advisory team, consisting of a surgeon, radiation oncologist and medical oncologist, in order to assess the prospects of the eventual adjuvant treatment. All patients underwent a general clinical examination and blood counts. The patients with heart, liver or renal diseases and those with poor performance status ( $\geq 2$ according to the World Health Organization - WHO) were assessed as non-eligible for the adjuvant therapy. The investigations performed before the surgery to define the extent of the disease and to rule out metastatic disease, such as esophagogastroduodenoscopy, endoscopic ultrasound (EUS) of tumour areas, computer tomography (CT) of the thorax or abdomen, and PET-CT, were repeated only in the patients in whom the progression of the disease was clinically suspected.

During the therapy, the patients were clinically examined and referred to haematology and biochemistry blood tests once a week. The therapyrelated local and systemic toxicity was assessed according to National Cancer Institute Common Toxicity Criteria (NCI-CTC) version 2.0. ${ }^{23}$ The performance status of patients was determined and their body weight was measured on the weekly basis. During the treatment all patients were monitored by the nutritionist as well.

\section{Postoperative radiochemotherapy}

The adjuvant treatment was initiated six to eight weeks after the surgery. The treatment schedule 


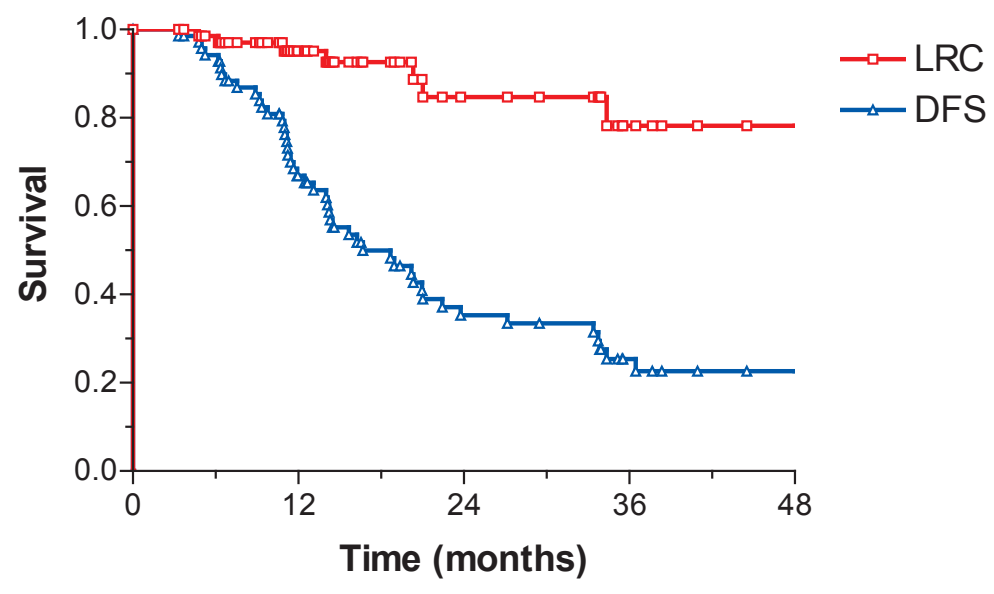

FIGURE 1. Locoregional control (LRC) and disease-free survival (DFS).

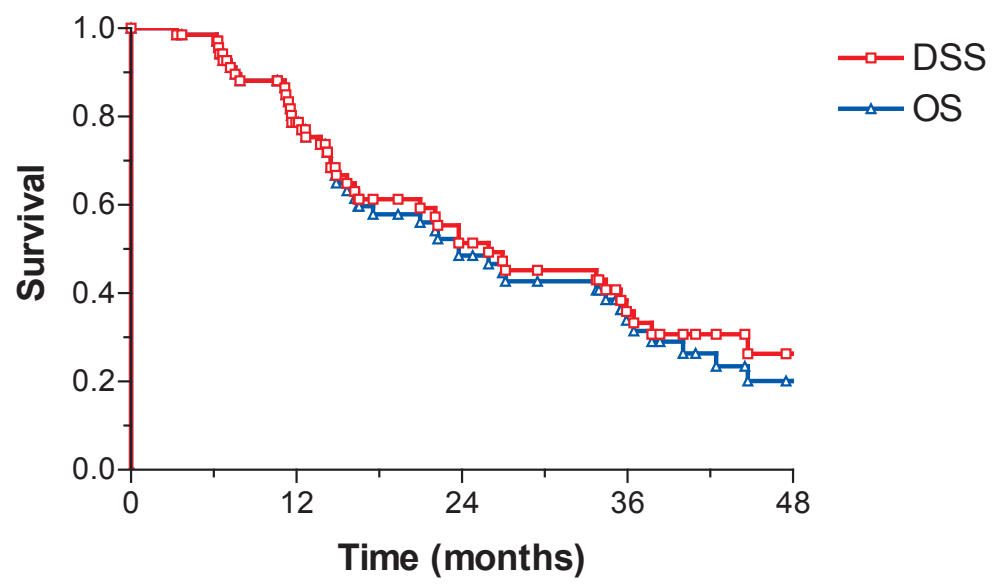

FIGURE 2. Disease-specific survival (DSS) and overall survival (OS).

included 6 cycles of chemotherapy with 5-FU (1000 $\left.\mathrm{mg} / \mathrm{m}^{2}\right)$ in 96 hours continuous infusion and cisplatin $\left(75 \mathrm{mg} / \mathrm{m}^{2}\right)$ in a bolus on day 2 of each cycle. The treatment cycle was repeated every 28 days. Chemotherapy administration required hospitalization for appropriate monitoring, hydration, antiemetic therapy and other supportive treatment. Radiotherapy was supposed to start at the beginning of the second cycle. Three-dimensional conformal radiotherapy was performed using $15 \mathrm{MV}$ photon beam linear accelerator. A prescribed dose was $45 \mathrm{~Gy}$ with daily fraction of $1.8 \mathrm{~Gy}$, five times per week. The dose specification was based on the International Commission on Radiation Units (ICRU) Report 50 recommendations. ${ }^{21}$ Treatment field borders were based on pretreatment investigations and imaging and postoperative anatomy, with tumour bed and regional lymph node areas included. Dose-volume histograms were checked to verify that radiation plans were optimized regarding target coverage and normal tissue sparing. The position of individual irradiation fields was checked on the weekly basis.

In case of severe therapy-related toxicity, irradiation and/or chemotherapy doses were modified and adapted to the patient's physical condition or laboratory tests. When necessary, chemotherapy application was delayed, or radiotherapy was temporarily interrupted or terminated.

\section{Follow-up}

After the completion of the treatment, patients performed regular follow-up visits. Physical examination and routine laboratory tests with tumour markers CEA, Ca 19-9 and Ca 72-4 were made every three months for the first two years after the treatment, every sixth months between two and five years after the treatment and thereafter once a year. Imaging investigations, CT of the thorax and abdomen and/or US of abdomen and chest X-ray, were performed two times per year for the first two years of the follow-up and then once a year. In case of suspected recurrence of the disease, other investigations such as endoscopy, EUS, magnetic resonance imaging of suspected area and PET-CT, were also performed.

\section{Statistical analysis and ethical consideration}

The statistical analysis was performed using personal computer and software statistical package SPSS, version 18 (SPSS Inc., USA). LRC was defined as the period from the date of surgery till the local and/or regional recurrence, DFS till the local, regional or systemic recurrence, DSS till the death due to GEJ adenocarcinoma, and OS till the death from any cause, respectively. The survival of patients was computed from the date of surgery to the September 15, 2011 (close-out date). The survival probability was calculated using Kaplan-Meier estimate ${ }^{25}$, and the log rank test was used to evaluate the differences between individual groups of patients. ${ }^{26}$ Independent prognostic values of variables that appeared as statistically significant on univariate analysis were tested by multivariate Cox regression analysis model. ${ }^{27}$ Two-sided tests were used and the differences at $p<0.05$ were considered as statistically significant.

The retrospective study was carried out according to the Declaration of Helsinki. 
TABLE 2. Toxicity of adjuvant radiochemotherapy

\begin{tabular}{lllllll}
\hline \multirow{2}{*}{ Toxicity } & \multicolumn{7}{c}{$\mathrm{NCl}$ grade (\%) } \\
\cline { 2 - 7 } & $\mathbf{0}$ & $\mathbf{1}$ & $\mathbf{2}$ & $\mathbf{3}$ & $\mathbf{4}$ & total \\
Stomatitis & 87.1 & 5.7 & 4.3 & 2.9 & 0 & 100 \\
\hline Radiodermatitis & 97.1 & 1.4 & 1.4 & 0 & 0 & 100 \\
Diarrhoea & 74.3 & 21.4 & 4.3 & 0 & 0 & 100 \\
Dysphagia & 31.4 & 18.6 & 15.7 & 34.3 & 0 & 100 \\
Nausea, vomiting & 14.3 & 28.6 & 18.6 & 38.6 & 0 & 100 \\
Infection & 28.6 & 5.7 & 24.3 & 38.6 & 2.9 & 100 \\
Leucocyte count & 17.1 & 15.7 & 35.7 & 27.1 & 4.3 & 100 \\
Haemoglobin level & 8.6 & 57.1 & 31.4 & 2.9 & 0 & 100 \\
Platelet count & 60 & 28.6 & 7.1 & 2.9 & 1.4 & 100 \\
\hline
\end{tabular}

\section{Results}

\section{Outcome of disease}

The median follow-up time of all 70 patients was 17.7 months (range: 3.3-64 months), whereas in survivors it was 27 months (range: 3.7-64 months). On the close-out date, $27(38.6 \%)$ patients were still alive, $20(28.6 \%)$ of them being with no signs of disease. Thirty-nine $(55.7 \%)$ patients died from GEJ adenocarcinoma, and in $4(5.7 \%)$ patients the cause of death could not be determined.

After adjuvant radiochemotherapy, the recurrence was observed in $46(65.6 \%)$ patients. Local and/or regional recurrence developed in two $(2.8 \%)$ patients at 20.3 and 33.4 months after the end of the treatment. Locoregional and systemic disease was observed in five (7.1\%) patients in the median period of time of 11.4 months (range: $4.8-21$ months), and distant metastases alone developed in $39(55.7 \%)$ patients in the median period of time of 11.9 months (range: 3.3-36.5 months).

Median LRC was not reached. Median DFS, DSS and OS were 16.7 months (95\% C.I.: 10-23.4), 25.9 (95\% C.I.: 13.7-38.2) and 23.8 months (95\% C.I.: $17-$ 30.5), respectively. At 3 years LRC, DFS, DSS and OS were $78.2 \%, 25.3 \%, 35.8 \%$, and $33.9 \%$, respectively (Figures 1 and 2).

\section{Toxicity of adjuvant radiochemotherapy}

Postoperative chemotherapy started in the median time of 6 weeks (range: 4.4-10.7 weeks) after the surgery. The total postoperative treatment time ranged from 0.5 to 25.6 weeks (median 14.6 weeks), whereas the duration of the radiotherapy part of the protocol ranged from 1-5.6 weeks (median 5 weeks). Twenty-six patients (37.1\%) completed the treatment according to the protocol. Sixty-seven patients $(87.1 \%)$ reached the total radiation dose of $45 \mathrm{~Gy}$, whereas in six patients $(8.4 \%)$ the total delivered dose was lower (from 9-27 Gy). Three $(4.3 \%)$ patients did not even start with the radiotherapy because of the side effects during the first cycle of chemotherapy. All six cycles of chemotherapy were administered in 26 patients $(37.1 \%), 7$ patients $(10 \%)$ received five, 16 patients $(22.9 \%)$ four, and 21 patients (30\%) three cycles or less. No death occurred due to the therapy. Acute toxicity grade 3 or more, such as stomatitis, dysphagia, nausea and/or vomiting, and infection, occurred in $2.9 \%$, $34.3 \%, 38.6 \%$ and $41.5 \%$ of patients, respectively (Table 2).

In $4(5.7 \%)$ patients, an increase of body weight was recorded during the therapy, $5(7.1 \%)$ patients maintained constant weight, whereas the remaining $61(87.2 \%)$ patients lost their weight with respect to the weight they had at the beginning of the treatment. The maximum body weight loss was $20.5 \%$ (median $7.5 \%$ ). Supplementary enteral nutrition was administered to $51(72.9 \%)$ patients and for $20(28.6 \%)$ patients parenteral nutrition was needed at least once during the treatment.

\section{Prognostic factors}

In patients in whom splenectomy was performed as well, DFS ( $p=0.033)$, DSS $(p=0.032)$ and OS $(p=0.016)$ were lower. Patients with the higher number of involved lymph nodes (stage N2 or N3) had lower DFS $(\mathrm{p}=0.022)$ and OS $(\mathrm{p}=0.026)$. Patients with weight loss $>5 \mathrm{~kg}$ before the operation had lower DSS $(p=0.032)$ and OS $(p=0.022)$. Patients with advanced disease (stage IIIb, IIIc) and patients with perineurial invasion had lower OS $(\mathrm{p}=0.025$ and $\mathrm{p}=0.044$, respectively). We did not find any differences in the survival regarding tumour localization classified by Siewert, tumour differentiation, type of the surgery and surgical specimen margins (R0 vs. R+). Older patients (aged 60 years or more) had higher DSS $(p=0.045)$ and OS $(p=0.053)$. Patients with levels of CEA more than $2 \mu \mathrm{g} / \mathrm{L}$ at the beginning of the postoperative treatment had lower DSS $(p=0.023)$ and OS $(p=0.028)$. Patients with levels of Ca $19-9$ more than $20 \mathrm{kU} / \mathrm{L}$ at the beginning of the postoperative treatment had lower LRC, DFS, DSS and OS ( $\mathrm{p}=0.018, \mathrm{p}=0.001, \mathrm{p}=0.007$ and $\mathrm{p}=0.017$, respectively).

In the multivariate analysis of the survival, splenectomy and level of Ca 19-9 $>20 \mathrm{kU} / \mathrm{L}$ before the 
TABLE 3. Multivariate analysis of survival

\begin{tabular}{|c|c|c|c|c|c|}
\hline \multirow{2}{*}{ Prognostic factors } & \multirow{2}{*}{ n } & $\begin{array}{l}\text { Locoregional } \\
\text { control }\end{array}$ & $\begin{array}{l}\text { Disease free } \\
\text { survival }\end{array}$ & $\begin{array}{l}\text { Disease specific } \\
\text { survival }\end{array}$ & $\begin{array}{l}\text { Overall } \\
\text { survival }\end{array}$ \\
\hline & & $\mathbf{p}$ & $\mathbf{p}$ & $\mathbf{p}$ & $\mathbf{p}$ \\
\hline \multicolumn{6}{|l|}{ pT-stage } \\
\hline $\begin{array}{l}\text { pT } 1+2 \\
\text { pT } 3+4\end{array}$ & $\begin{array}{l}48 \\
75\end{array}$ & & & 0.03 & \\
\hline \multicolumn{6}{|l|}{ pN-stage } \\
\hline $\begin{array}{l}\mathrm{pN} 0+1+2 \\
\mathrm{pN} 3\end{array}$ & $\begin{array}{l}98 \\
25\end{array}$ & & & & \\
\hline \multicolumn{6}{|l|}{ Overall stage } \\
\hline $\begin{array}{l}\text { Stage Ib -III } \\
\text { Stage IV }\end{array}$ & $\begin{array}{l}93 \\
30\end{array}$ & 0.05 & & & \\
\hline \multicolumn{6}{|l|}{ Stomach involvement } \\
\hline $\begin{array}{l}\text { Whole stomach } \\
\text { Individual areas }\end{array}$ & $\begin{array}{c}7 \\
116\end{array}$ & & & & \\
\hline \multicolumn{6}{|l|}{ Primary tumour site } \\
\hline $\begin{array}{l}\text { Cardia } \\
\text { Other sites }\end{array}$ & $\begin{array}{c}16 \\
107\end{array}$ & & & & \\
\hline \multicolumn{6}{|l|}{ Perineurial invasion } \\
\hline $\begin{array}{l}\text { Yes } \\
\text { No }\end{array}$ & $\begin{array}{l}45 \\
59\end{array}$ & & & & \\
\hline \multicolumn{6}{|l|}{ Angioinvasion } \\
\hline $\begin{array}{l}\text { Yes } \\
\text { No }\end{array}$ & $\begin{array}{l}45 \\
23\end{array}$ & & 0.07 & & \\
\hline \multicolumn{6}{|l|}{ Initial Hb level } \\
\hline $\begin{array}{l}\mathrm{Hb} \text { start } \leq 110 \mathrm{~g} / \mathrm{l} \\
\mathrm{Hb} \text { start }>110 \mathrm{~g} / \mathrm{l}\end{array}$ & $\begin{array}{l}24 \\
99\end{array}$ & 0.009 & 0.0001 & 0.02 & 0.01 \\
\hline \multicolumn{6}{|c|}{ 5-FU total dose per cycle } \\
\hline $\begin{array}{l}\leq 4000 \mathrm{mg} \\
>4000 \mathrm{mg}\end{array}$ & $\begin{array}{c}109 \\
14\end{array}$ & & 0.03 & 0.07 & \\
\hline
\end{tabular}

pT = pathological T-stage; $\mathrm{pN}=$ pathological N-stage; Hb start = haemoglobin concentration at the start of the therapy

adjuvant treatment were identified as independent prognostic factors for the lower DFS ( $\mathrm{p}=0.029$ and $\mathrm{p}=0.004)$, DSS $(\mathrm{p}=0.012$ and $\mathrm{p}=0.001)$ and OS $(\mathrm{p}=0.006$ and $\mathrm{p}<0.0001)$. Age $<60$ years, higher number of involved lymph nodes (stage N2 or N3) and advanced disease stage (stage IIIb or IIIc) were identified as independent prognostic factors for the lower DSS $(p=0.009, p=0.019$ and $p=0.006$, respectively) and OS ( $\mathrm{p}=0.005, \mathrm{p}=0.014$ and $\mathrm{p}=0.003$, respectively) (Table 3 ).

\section{Discussion}

Patients with GEJ adenocarcinomas treated with surgery only have a very poor prognosis with a 5-year survival rate of approximately $20 \% .28,29$ Many authors proved that the combined radio- therapy and chemotherapy, applied preoperatively, postoperatively or at inoperable patients might significantly improve the survival of these patients. ${ }^{10,11,13,14,18,30}$ In our study the retrospective analysis of 70 patients with GEJ adenocarcinomas treated with postoperative radiochemotherapy was performed. The radical resection was performed in $80 \%$ of our patients, which could be comparable to results of other published studies. ${ }^{31-34}$ In our study the 3-year LRC, DFS, DSS and OS results should not be compared with results of MacDonald et al. ${ }^{13}$, because the majority of patients in his study had stomach carcinoma and only $20 \%$ patients had GEJ carcinoma. The subanalysis for those patients was not performed. The other reason why the data are not comparable is the use of different cytostatics; in MacDonald's study chemotherapy included 5-FU and leucovorin and in our study 5-FU and cispl- 
atin were administered. In MacDonald's study, patients treated with postoperative radiochemotherpy had 48\% 3-years DFS and 50\% 3-years OS. The study of Adelstein et al. ${ }^{31}$ in which 50 patients with carcinomas of oesophagus and GEJ treated with postoperative radiochemotherapy with 5-FU and cisplatin were included, reported that 4-year LRC, DFS and OS were $86 \%, 50 \%$ and $51 \%$. These results are better than ours, but in their study also patients with less advanced disease and, therefore, a better prognosis were included.

Although one of the critique of the American intergroup study ${ }^{13}$ was referred to the high percentage of patients $(36 \%)$, who did not complete the regimen, in our study only $37 \%$ finished the therapy according to the protocol. While most of our patients received full radiation therapy $(87.1 \%)$, all six cycles of chemotherapy were applied in only 26 patients $(37.1 \%)$. The most common toxic side effects classified as grade 3 or higher were, as in MacDonald's study ${ }^{13}$, gastrointestinal toxic effects, infections and leucopenia. In Adelstein's study ${ }^{31}$ only 3 patients did not finished the treatment according to the protocol, but their schedule contained only 2 cycles while our schedule contained 6 cycles of chemotherapy with 5-FU and cisplatin. Therefore, greater toxicity and more treatment interruptions in our study were expected.

Our analysis demonstrated that patients with the involvement of numerous lymph nodes and more advanced stage of disease have a lower survival. These are well known factors that have an impact on the survival of patients with GEJ carcinoma. ${ }^{35-41}$

Tumour origin (tumour localization classified by Siewert), tumour differentiation, type of surgery and positive surgical margins did not have any impact on the outcome as in some other series as well. ${ }^{31,42}$ On the other hand, some other authors reported that patients with GEJ adenocarcinomas Siewert type I have a better prognosis because they have an earlier onset of symptoms (like dysphagia) and are, therefore, diagnosed in earlier stages. They also argued that poor differentiation of tumours has negative effect on the survival due to the increased risk of lymphatic dissemination and that the presence of tumour cells in the resected margins could have a negative impact on the survival of operated patients. ${ }^{35}$

Weight loss is a common symptom of GEJ cancer. It is due to the mechanical effects of the tumour that causes dysphagia, early satiety, nausea and vomiting. Beside this, systemic influences like hypermetabolism, anorexia and altered protein me- tabolism, have an important role in the nutritional status of these patients..$^{43}$ In our study, weight loss of more than $5 \mathrm{~kg}$ before the operation was associated with the lower DFS, DSS and OS. In several other studies - not only at patients with GEJ adenocarcinoma - weight loss before the treatment was a negative prognostic factor. ${ }^{42,44-47}$ In a large study of patients with oesophageal cancer, weight loss greater than $10 \%$ of pre-morbid weight was the only significant predictor of early death in patients undergoing the surgical resection..$^{45}$

Our analysis demonstrated the survival benefit for patients older than 60 years. Similar results were described in the study of Crumley et al. who found that patients older than 65 years had better 3-year survival than younger patients (32\% vs. $29 \%$; $p=0.017) .{ }^{42}$ Some other studies did not find any prognostic significance between different groups of age. .8-51 $^{-1}$

The multivariate analysis also identified splenectomy as a negative prognostic factor. In several published studies splenectomy had a negative impact on the survival, ${ }^{52-53}$ while other studies did not demonstrate marked effect on the survival. ${ }^{33,34,54}$ The need for splenectomy in patients with GEJ is still controversial. Compared with a gastric cancer, in GEJ cancer lymph node metastases in the splenic hilum are more frequent and that is why some surgeons consider splenectomy as necessary. 55,56 However, splenectomy is known to be associated with increased morbidity after the resection of proximal gastric and GEJ cancer, especially due to a higher risk of infections.

One of the independent prognostic factors in our study was also the level of Ca 19-9 more than $20 \mathrm{kU} / \mathrm{L}$ before the start of the postoperative treatment. Elevated tumour markers are known to be associated with the higher probability of lymph node metastases, lymphatic and blood vessel invasion, depth of invasion, higher stage and dissemination of the disease. Kočevar et al. ${ }^{57}$ reported that translationally controlled tumour protein (TPT1) was shown to be differentially expressed only in patients GEJ cancer, but, it clinical have to be established.

\section{Conclusions}

Postoperative radiochemotherapy for GEJ is an attractive approach for several reasons since the treatment decision is based on the true pathologic stage and hence a more accurate assessment of the disease extent. On the other hand, it also has some 
disadvantages, such as difficult recovery of some patients after extensive resections and worse blood supply and oxygenation of tumour bed and, therefore, less effective treatment with radiochemotherapy. However, even if we consider that preoperative radiochemotherapy can improve resectability and, therefore, enables us the higher proportion of curative resections, postoperative radiochemotherapy is still reserved for the selected group of patients, who first underwent surgery due to different reasons.

\section{References}

1. Siewert JR, Stein HJ. Classification of adenocarcinoma of the oesophagogastric junction. Br J Surg 1998; 85: 1457-9.

2. Parkin DM, Bray F, Ferlay J, Pisani P. Global cancer statistic, 2002. CA cancer J Clin 2005; 55: 74-108.

3. American Joint Committee on Cancer. AJCC cancer staging manual, 7th edition. New York: Springer-Verlag; 2009.

4. Wronski M, Ziarkiewicz-Wroblewska B, Slodkowski M, Cebulski W, Gornicka B Krasnodebski IW. Mesenteric fibromatosis with intestinal involvement mimicking a gastrointestinal stromal tumour. Radiol Oncol 2011; 45: 59-63.

5. Oblak I, Velenik V, Anderluh F, Strojan P. Results of adjuvant radiochemotherapy for gastric adenocarcinoma in Slovenia. Eur J Surg Oncol 2007; 33: 982-7.

6. Oblak I, Anderluh Franc, Velenik V. Postoperative radiochemotherapy for gastric adenocarcinoma: long term results. Radiol Oncol 2009; 43: 274-81.

7. Power DG, Reynolds JV. Localized adenocarcinoma of the esophagogastric junction-is there a standard of care? Cancer Treatm Rev 2010; 36: 400-9.

8. Wayman J, Bennet MK, Rames SA, Griffin SM. The pattern of recurrence of adenocarcinoma of the oesophagogastric junction. Br J Cancer 2002; 86: 1223-9.

9. Schuhmacher C, Gretschel S, Lordick F, Reichardt P, Hohenberger W, Eisenberger $\mathrm{CF}$, et al. Neoadjuvant chemotherapy compared with surgery alone for locally advanced cancer of the stomach and cardia: European Organisation for Research and Treatment of Cancer randomized trial 40954 I Clin Oncol 2010; 28: 5210-8.

10. Walsh TN, Noonan N, Hollywood D, Kelly A, Keeling N, Hennessy TP. A comparison of multimodal therapy and surgery for esophageal adenocarcinoma. N Engl J Med 1996; 335: 462-7.

11. Tepper J, Krasna MJ, Niedzwiecki D, Hollis D, Reed CE, Goldberg R, et al. Phase III trial of trimodality therapy with cisplatin, fluorouracil, radiotherapy and surgery compared with surgery alone for esophageal cancer: CALGB 9781. J Clin Oncol 2008; 26: 1086-92.

12. Ajani JA, Rodriguez W, Bodoky G, Moiseyenko V, Lichinitser M, Gorbunova $\mathrm{V}$, et al. Multicenter phase III comparison of cisplatin/S-1 with cisplatin/infusional fluorouracil in advanced gastric or gastroesophageal adenocarcinoma study: the FLAGS trial. J Clin Oncol 2010; 28: 1547-53.

13. Macdonald JS, Smalley SR, Benedetti J, HundahI SA, Estes NC, Stemmermann $\mathrm{G}$, et al.. Chemoradiotherapy after surgery compared with surgery alone for adenocarcinoma of the stomach or gastroesophageal junction. N Engl J Med 2001; 345: 725-30.

14. Kim S, Lim DH, Lee J, Kang WK, MacDonald S, Park CH, et al. An observational study suggesting clinical benefit for adjuvant postoperative chemoradiation in a population of over 500 cases after gastric resection with D2 nodal dissection for adenocarcinoma of the stomach. Int J Radiat Oncol Biol Phys 2005; 63: 1279-85.

15. Cunningham D, Allum WH, Stenning SP, Thompson JN, Van de Velde $\mathrm{CJ}$ Nicolson $\mathrm{M}$, et al. Perioperative chemotherapy versus surgery alone for resectable gastroesophageal cancer. N Engl J Med 2006; 335: 11-20.
16. Ychou M, Boige V, Pignon JP, Conroy $T$, Bouché $\mathrm{O}$, Lebreton $\mathrm{G}$, et al Perioperative chemotherapy compared with surgery alone for resectable gastroesophageal adenocarcinoma: an FNCLCC and FFCD multicenter phase III trial. J Clin Oncol 2011; 29: 1715-21.

17. Stahl M, Walz MK, Stuschke M, Lehmann N, Meyer HJ, Riera-Knorrenschild J, et al. Phase III comparison of preoperative chemotherapy compared with chemoradiotherapy in patients with locally advanced adenocarcinoma of the esophagogastric junction. J Clin Oncol 2009; 27: 851-6.

18. Gebski V, Burmeister B, Smithers BM, Foo K, Zalcberg J, Simes J; Australasian Gastro-Intestinal Trials Group. Survival benefits from neoadjuvant chemoradiotherapy or chemotherapy in oesophageal carcinoma: a meta-analysis. Lancet Oncol 2007; 8: 226-34.

19. Fok M, Sham JS, Choy D, Cheng SW, Wong J. Postoperative radiotherapy for carcinoma of the esophagus: a prospective, randomized controlled study. Surgery 1993; 173: 138-47

20. Teniere P, Hay JM, Fingerhut A, Fagniez PL. Postoperative radiation therapy does not increase survival after curative resection for squamous cell carcinoma of the middle and lower esophagus as shown by a multicenter controlled trial. French university association for surgical research. Surg Gynecol Obstet 1991; 173: 123-30.

21. Sun $\mathrm{P}$, Xiang JB, Chen ZY. Meta-analysis of adjuvant chemotherapy after radical surgery for advanced gastric cancer. Br J Surg 2009; 96: 23-33.

22. Liu TS, Wang Y, Chen SY, Sun YH. An updated meta-analysis of adjuvant chemotherapy after curative resection for gastric cancer. Eur J Surg Oncol 2008; 34: 1208-16.

23. Ajani JA, Welch SR, Raber MN, Fiels WS, Krakoff IM. Comprehensive criteria for assessing therapy-induced toxicity. Cancer Invest 1990; 8: 147-59.

24. ICRU 50: Prescribing, recording, and reporting photon beam therapy Bethesda: International Commission on Radiation Units and Measurements Press; 1993.

25. Kaplan EL, Meier P. Nonparametric estimation from incomplete observations. J Am Stat Assoc 1958; 53: 457-81.

26. Peto R, Pike MC, Armitage P. Design and analysis of randomized clinical trials requiring prolonged observation of each patient. II. Analysis and examples. Br J Cancer 1977; 35: 1-39.

27. Cox DR. Regression models and life-tables. J R Stat Soc Bull 1972; 34: 187220.

28. Enzinger PC, Mayer RJ. Esophageal cancer. N Eng/ J Med 2003; 349: 2241-52.

29. Pisani P, Parkin DM, Ferlay J. Estimates of the worldwide mortality from 18 major cancers in 1985. Int J Cancer 1993; 55: 891-903.

30. Torrente S, Turri L, Deantonio L, Cena T, Gambaro G, Magnani C, et al. Concomitant chemo-radiotherapy for unresectable oesophageal cancer: A mono-institutional study on 40 patients. Rep Pract Oncol Radiother 2012; 17: $226-32$

31. Adelstein DJ, Rice TW, Rybicki LA, Saxton JP, Videtic GMM, Murthy SC, et al. Mature results from a phase II trial of postoperative concurrent chemoradiotherapy for poor prognosis cancer of the esophagus and gastroesophagea junction. J Thorac Oncol 2009; 4: 1264-9.

32. Feith M, Stein HJ, Siewert JR. Adenocarcinoma of the esophagogastric junction: surgical therapy based on 1602 consecutive resected patients. Surg Oncol Clin N Am 2006; 15: 751-64.

33. Weitz J, Jaques DP, Brennan M, Karpeh M. Association of splenectomy with postoperative complications in patients with proximal gastric and gastroesophageal junction cancer. Ann Surg Oncol 2004; 11: 682-9.

34. Pultrum BB, van Bastelaar J, Schreurs MA, van Dullemen $H M$, Groen $H_{,}$ Nijsten MWN, et al. Impact of splenectomy on surgical outcome in patients with cancer of the distal esophagus and gastro-esophageal junction. Dis Esophagus 2008; 21: 334-9.

35. Lagarde SM, ten Kate FJ, Reitsma JB, Busch OR, van Lanschot JJ. Prognostic factors in adenocarcinoma of the esophagus or gastroesophageal junction. J Clin Oncol 2006; 24: 4347-55.

36. Eloubeidi MA, Desmond R, Arguedas MR, Reed CE, Wilcox CM. Prognostic factors for the survival of patients with esophageal carcinoma in the US. Cancer 2002: 95: 1434-43. 
37. Steup WH, de Leyn P, Deneffe G, van Raemdonck D, Coosemans W, Lerut $T$. Tumors of the esophagogastric junction. Long-term survival in relation to the pattern of lymph node metastasis and a critical analysis of the accuracy or inaccuracy of pTNM classification. $J$ Thorac Cardiovasc Surg 1996; 111: 85-94.

38. Mariette C, Taillier G, van Seuningen I, Triboulet JP. Factors affecting postoperative course and survival after en bloc resection for esophageal carcinoma. Ann Thorac Surg 2004; 78: 177-83.

39. Lerut T, Coosemans W, Decker G, de Leyn P, Moons J, Nafteux P, et al. Extended surgery for cancer of the esophagus and gastroesophageal junction. J Surg Res 2004; 117: 58-63.

40. Predrazzani C, de Manzoni G, Marrelli D, Giacopuzzi S, Corso G, Minicozzi AM, et al. Lymph node involvement in advanced gastroesophageal junction adenocarcinoma. J Thorac Cardiovasc Surg 2007; 134: 378-85.

41. Siewert JR, Feith M, Werner M, Stein HJ. Adenocarcinoma of the esophagogastric junction: results of surgical therapy based on anatomical/topographic classification in 1002 consecutive patients. Ann Surg 2000; 232: 353-61.

42. Crumley ABC, Stuart RC, McKernan M, Going JJ, Shearer CJ, McMilan DC Comparison of the pre-treatment clinical prognostic factors in patients with gastro-oesophageal cancer and proposal of a new staging system. $J$ Gastrointest Surg 2010; 14: 781-7.

43. Deans DAC, Tan BH, Wigmore SJ, Ross JA, de Beaux AC, Paterson-Brown S, et al. The influence of systemic inflammation, dietary intake and stage of disease on rate of weight loss in patients with gastro-oesophageal cancer. BrJ Cancer 2009; 100: 63-9.

44. Stahl M, Wilke $H$, Stuschke $M$, Walz MK, Fink U, Molls $M$, et al. Clinical response to induction chemotherapy predicts local control and long-term survival in multimodal treatment of patients with locally advanced esophageal cancer. J Cancer Res Clin Oncol 2005; 131: 67-72.

45. Kelsen DP, Ginsberg R, Pajak TF, Sheahan DB, Gunderson L, Mortimer J, et al. Chemotherapy followed by surgery compared with surgery alone for localized esophageal cancer. . N Engl J Med 1998; 339: 1979-84.

46. Plaisant N, Senesse P, Azria D, Lemanski C, Ychou M, Quenet F, et al. Surgery for esophageal cancer after concomitant radiochemotherapy: oncologic and functional results. World I Surg 2005; 29: 32-8.

47. Kovac V, Zwitter M, Zagar T. Improved survival after introduction of chemotherapy for malignant pleural mesothelioma in Slovenia: Population-based survey of 444 patients. Radiol Oncol 2012; 46: 136-44.

48. Leigh Y, Seagroatt V, Goldacre M, McCulloch P. Impact of socio-economic deprivation on death rates after surgery for upper gastrointestinal tract cancer. Br J Cancer 2006; 95: 940-3.

49. Sabel MS, Smith JL, Nava HR, Mollen K, Douglass HO, Gibbs JF. Esophageal resection for carcinoma in patients older than 70 years. Ann Surg Oncol 2002; 9: 210-4.

50. McKernan M, McMillan DC, Anderson JR, Angerson WJ, Stuart RC. The relationship between quality of life (EORTC QLQ-C30) and survival in patients with gastro-oesophageal cancer. Br J Cancer 2008; 98: 888-93.

51. Sauvanet A, Mariette C, Thomas P, Lozac'h P, Segol P, Tiret E, et al. Mortality and morbidity after resection for adenocarcinoma of the gastroesophageal junction: predictive factors. J Am Coll Surg 2005; 201: 253-62.

52. Cuschieri A, Weeden S, Fielding J, Bancewicz J, Craven J, Joypaul V, et al. Patient survival after D1 and D2 resections for gastric cancer: long-term results of the MRC randomized surgical trial. Surgical Co-operative Group. Br J Cancer 1999; 79: 1522-30.

53. Schmid A, Thybusch A, Kremer B, Henne-Bruns D. Differential effects of radical D2-lymphadenectomy and splenectomy in surgically treated gastric cancer patients. Hepatogastroenterology 2000; 47: 579-85.

54. Huang CM, Wang JB, Lu HS, Zheng CH, Li P, Xie JW, et al. Prognostic impact of splenectomy on advanced proximal gastric cancer with more than 10 lymph node metastasis. Chin Med J 2009; 122: 2757-62.

55. Buyukasik O, Hasdemir AO, Gulnerman Y, Col1 C, Ikiz O. Second primary cancers in patients with gastric cancer. Radiol Oncol 2010; 44: 239-43.

56. Ikequchi M, Kaibara N. Lymph node metastasis at the splenic hilum in proximal gastric cancer. Am Surg 2004; 70: 645-8.

57. Kočevar N, Odreman F, Vindigni A, Grazio SF, Komel R. Proteomic analysis of gastric cancer and immunoblot validation of potential biomarkers. World J Gastroenterol 2012; 18: 1216-28. 